\title{
Neutrophil roles in left ventricular remodeling following myocardial infarction
}

\author{
Yonggang $\mathrm{Ma}^{1,2^{*}}$, Andriy Yabluchanskiy ${ }^{1,2}$ and Merry L Lindsey ${ }^{1,2,3^{*}}$
}

\begin{abstract}
Polymorphonuclear granulocytes (PMNs; neutrophils) serve as key effector cells in the innate immune system and provide the first line of defense against invading microorganisms. In addition to producing inflammatory cytokines and chemokines and undergoing a respiratory burst that stimulates the release of reactive oxygen species, PMNs also degranulate to release components that kill pathogens. Recently, neutrophil extracellular traps have been shown to be an alternative way to trap microorganisms and contain infection. PMN-derived granule components are also involved in multiple non-infectious inflammatory processes, including the response to myocardial infarction (MI). In this review, we will discuss the biological characteristics, recruitment, activation, and removal of PMNs, as well as the roles of PMN-derived granule proteins in inflammation and innate immunity, focusing on the MI setting when applicable. We also discuss future perspectives that will direct research in PMN biology.
\end{abstract}

Keywords: PMNs, Myocardial infarction, Inflammation, Innate immunity, Degranulation, Matrix metalloproteinases

\section{Review}

\section{Introduction}

Polymorphonuclear granulocytes (PMNs; neutrophils) are a type of leukocyte of approximately $10 \mu \mathrm{m}$ in diameter that play vital roles in the innate immunity response to pathogens. PMNs are the first responders to infection or injury. Persistent neutropenia leads to increased risk of microorganism infections, while excessive recruitment and activation or delayed removal of PMNs results in tissue damage in inflammatory disorders [1]. Following myocardial infarction (MI), numbers of circulating PMNs increase, and the post-MI PMN to lymphocyte ratio has been reported by Akpek and colleagues to predict major adverse cardiac events in MI patients [2]. While PMN counts do not improve the ability to diagnose MI, they are a prognostic biomarker of chronic remodeling of the left ventricle (LV) [3]. Increased PMN counts after percutaneous coronary intervention for ST-elevation MI associates with larger infarct sizes and worse cardiac function [4]. Neutrophil depletion reduces infarct size and the extent of injury in a canine model $[5,6]$. As such, PMNs have been shown to mediate MI-induced cardiac injury

\footnotetext{
* Correspondence: yma@umc.edu; mllindsey@umc.edu

'San Antonio Cardiovascular Proteomics Center, San Antonio, TX, USA ${ }^{2}$ Jackson Center for Heart Research, Department of Physiology and Biophysics, University of Mississippi Medical Center, Jackson, MS, USA Full list of author information is available at the end of the article
}

and remodeling. However, the potential mechanisms by which neutrophils regulate MI-induced LV remodeling are not well understood, and PMN depletion strategies in humans increased adverse outcomes post-MI [7]. This review will discuss our current understanding of PMN biology, including recruitment, activation, clearance, and function. We also discuss the roles of PMN-derived components in inflammation and innate immunity, focusing on the MI setting. In addition, we propose future directions that may advance the PMN research arena.

\section{Biological characteristics of PMNs}

PMNs are the most abundant leukocyte cell type in mammals, accounting for $\sim 35-75 \%$ of circulating leukocytes under normal conditions [8]. PMNs are the first-line immune cells recruited to sites of injury as a defense against microorganisms. PMN microbicidal mechanisms include receptor-mediated phagocytosis and intracellular killing, release of antimicrobial granule contents by degranulation, and the formation of neutrophil extracellular traps (NETs) [9]. In addition to their antimicrobial activity, growing evidence suggests that PMNs play an essential role in non-infectious inflammation, innate immunity, and tissue remodeling [10].

Based on ex vivo evaluation, murine and human PMNs have a circulating lifespan of 5-10 h [11,12]. However, 
recent work by Pillay and colleagues using in vivo PMN labeling has shown that the circulating lifespan of human PMNs can last up to 5.4 days, indicating that in vivo characteristics of PMNs may be altered by ex vivo manipulation or that in vivo stimuli can prevent PMN apoptosis [13]. In the proinflammatory environment, for example, PMN lifespan can be prolonged by tumor necrosis factor (TNF)- $\alpha$ - or interleukin (IL)-1 $\beta$-stimulated inhibition of apoptosis [14].

PMN development and maturation take place in the bone marrow. In the presence of growth factors and cytokines, pluripotent hematopoietic cells differentiate into myeloblasts, which are the precursor cells of PMNs [15]. PMNs synthesize components stored in different granules as part of the maturation process [10]. It is estimated that PMNs are produced at $\sim 1 \times 10^{9}$ cells per kilogram body weight daily under physiological conditions [16]. Only $1-2 \%$ of mature PMNs circulate, while $98-99 \%$ remain in the bone marrow [17]. Circulating PMNs are mature, terminally differentiated cells that have lost their proliferative capacity. In response to a challenge, mature PMNs in the bone marrow mobilize into the blood and are recruited to injury sites. PMN chemoattraction is regulated by chemokines, cytokines, and microbial products [1].

\section{PMN extravasation and recruitment in response to $\mathrm{MI}$}

In the setting of MI, chemokines that recruit PMNs to sites of ischemia include macrophage inflammatory protein- $2 \alpha$ (MIP-2 $\alpha$, CXCL2, GRO $\beta$ ), leukotriene B4 (LTB4), CINC-1 (CXCL1, GRO $\alpha, \mathrm{KC})$, IL-8 (CXCL8), and complement 5a $[18,19]$. PMN-attracting CXC chemokines are rapidly and profoundly increased post-MI and have been localized bound to glycosaminoglycans on endothelial cell surfaces or in the extracellular matrix. The accumulation of high concentrations of chemokines at the ischemic site attracts PMNs to the injury area by interaction with cell surface chemokine receptors [20].

PMNs leave the circulation and infiltrate to the infarct region through several sequential steps, collectively known as extravasation. The extravasation of PMNs occurs primarily in post-capillary venules, where hemodynamic shear forces are diminished and the vessel wall is thin. As a first step, PMNs are arrested from the fast-flowing blood stream and roll on endothelial cells. This reaction is mediated through binding of P-selectin ligand 1 and L-selectin constitutively expressed on PMNs to P-selectin, E-selectin, intercellular adhesion molecules (ICAMs), and vascular cell adhesion molecules expressed by activated endothelial cells [15]. Second, firm adhesion occurs by interaction of the $\beta_{2}$ integrin lymphocyte function-associated antigen-1 $\left(\alpha_{\mathrm{L}} \beta_{2}, \mathrm{LFA}-1, \mathrm{CD} 11 \mathrm{a} / \mathrm{CD} 18\right)$ and macrophage-1 antigen (Mac-1, $\alpha_{M} \beta_{2}$, CD11b/CD18, CR3) present on PMNs with their ligands ICAM-1 and ICAM-2 on endothelial cells.
Next, PMN transendothelial migration takes place by paracellular or intracellular trafficking. While most PMNs squeeze between endothelial cells (paracellular trafficking), a small fraction penetrates and passes through pores in the cytoplasm of individual endothelial cell (intracellular trafficking) [15]. Mediators that guide migration are the same as those of firm adhesion, namely integrins $\alpha_{L} \beta_{2}$ and $\alpha_{M} \beta_{2}$, ICAM-1, and ICAM-2. PMN homing to the infarct site is similar to PMN extravasation into other tissues as part of a common wound healing response to injury.

In the absence of reperfusion, PMNs are the first inflammatory cells recruited to the infarct area. With permanent occlusion in C57BL/6J mice, PMN infiltration occurs within hours post-MI, peaks at days $1-3$, starts to decline at day 5 , and is present at very low levels from day 7 post-MI (Figure 1). As such, PMNs primarily regulate the early LV remodeling response. PMNs initiate the acute inflammatory response to engulf dead cells and tissue debris and facilitate post-MI repair. However, excessive PMN infiltration or delayed regression exacerbates tissue injury by the abundant release of inflammatory mediators and proteinases [21]. Hence, PMN infiltration and removal need to be tightly controlled.

\section{PMN activation post-MI}

In response to infection, PMNs can be activated by pathogen-associated molecular patterns from pathogens or danger-associated molecular patterns (DAMPs) from host tissue via engagement with pattern recognition receptors expressed on the surface or within the cytoplasm of PMNs. PMNs express a wide array of pattern recognition receptors, including 12 of the13 known toll-like receptors (TLRs; the exception is TLR3), C-type lectin receptors dectin 1 (CLEC7A) and CLEC2, NOD-like receptors (NLRs), and cytoplastic sensors of ribonucleic acids, including retinoic acid-inducible gene 1 (RIG-I) and melanoma differentiation-associated protein 5 (MDA5) [22-26]. Activated PMNs kill invading pathogens by the mechanisms of release of reactive oxygen species (ROS) and granule proteins, as well as NETs. However, uncontrolled PMN accumulation can lead to injury to host tissue and cells.

DAMPs are molecules that can initiate and perpetuate the immune response in non-infectious inflammatory conditions, and DAMPs are produced from host tissue or immune cells in response to stress or injury. MI-associated DAMPs include heat shock proteins, high-mobility group box (HMGB)-1, low molecular hyaluronic acid, and fibronectin fragments [27]. DAMPs, as endogenous danger signal and secondary injury-promoting factors, engage with pattern recognition receptors to activate PMNs, other immune cells, or parenchymal cells [28]. This leads to the development of a proinflammatory autocrine loop that can result in chronic or unresolved 

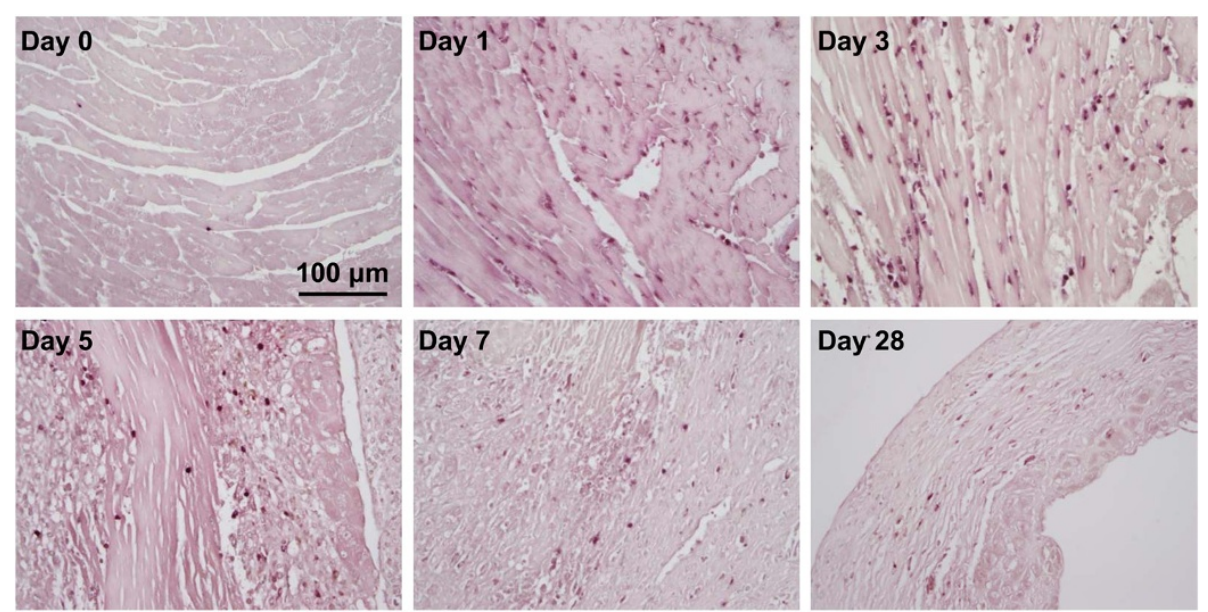

Figure 1 Time course of PMN infiltration post-MI. MI was created by permanent ligation of the left anterior descending coronary artery in C57BL/6J mice. Following MI, PMN infiltration peaked at days 1-3, started to decline at day 5, and was present at very low levels from day 7 postMI. PMNs were stained with anti-mouse neutrophil monoclonal antibody (Cederlane, CL8993AP, 1:100). Representative images from $n=3$ stained samples per group. Our own unpublished data.

inflammation. For example, HMGB1, an endogenous ligand for TLR2 and TLR4, is released both actively and passively by injured cells [29]. Injection of HMGB1 results in PMN accumulation, and an anti-HMGB1 blocking antibody inhibits PMN infiltration in lipopolysaccharide-induced lung injury [30]. HMGB1, therefore, promotes and sustains the inflammatory response.

\section{PMN clearance and resolution of inflammation}

Apoptotic PMNs are removed by macrophage- or dendritic cell-mediated phagocytosis. In the absence of infection or inflammation, PMN clearance occurs at significant rates in the spleen, liver, and bone marrow [31]. In response to infection or inflammation, PMNs can infiltrate in and be cleared from all tissues of the body [21]. PMN apoptosis as well as subsequent removal is a hallmark of inflammation resolution, an active process that requires activation of many inhibitory pathway cascades [20]. For example, apoptotic PMNs produce "find me" (e.g., lipid mediators and nucleotides) and "eat me" (e.g., lysophosphatidylcholine) signals to attract scavengers by at least two different mechanisms [20,21]. First, apoptotic PMNs generate annexin $\mathrm{A} 1$ and lactoferrin to inhibit PMN infiltration. Moreover, these two mediators attract phagocytic macrophages to remove PMNs. Second, phagocytosis of apoptotic PMNs by macrophages activates an antiinflammatory pathway to inhibit proinflammatory mediators (e.g., TNF- $\alpha$ ) and induce the production of IL-10, transforming growth factor- $\beta$ and pro-resolving lipid mediators such as lipoxins, protectins, and resolvins [32]. These pro-resolving mediators inhibit PMN transendothelial migration and scavenge chemokines and cytokines. Esmann and colleagues have recently shown that after exposure to activating stimuli (e.g., lipopolysaccharide and interferon- $\gamma$ ), PMNs, as a self-regulation mechanism, can ingest apoptotic PMNs and contribute to the resolution of acute inflammation [33]. If not removed in a timely manner, dying PMNs can liberate granule components to the extracellular environment and prolong the ongoing inflammatory response [21]. The importance of these mechanisms in the MI setting, however, needs to be investigated.

\section{ROS and MI}

Upon contact with proinflammatory stimuli (e.g., cytokines and growth factors), PMNs release large amounts of ROS through a process known as the respiratory burst [34]. The respiratory burst is mediated by nicotinamide adenine dinucleotide phosphate (NADPH) oxidase multicomponent enzyme. NAPDH oxidase is composed of a membranebound cytochrome b558 consisting of gp91phox and p22phox, cytosolic subunit p67phox, p47phox, and p40phox, and the small G-protein Rac (Rac1 or Rac2) [35]. In resting PMNs, the NAPDH oxidase complex is not assembled. Upon activation, these subunits assemble into an active enzyme complex that catalyzes the production of ROS [34].

The generation of ROS is an indispensable contributor of PMN antimicrobial activity and provides one of the most efficient microbicidal mechanisms [34]. NADPH oxidase increases ROS production. ROS can directly damage host tissue and cells by modifying amino acids, proteins, and lipids to alter their biological functions [10]. For example, ROS can oxidize cysteine residues to regulate the activities of phosphatases, metalloproteinases, and 
caspases [10]. Antioxidant pre-treatment in rats decreases microvascular density in the infarct region at day 7 post-MI , and inhibition of NADPH oxidase attenuates post-MI cardiac fibrosis in rats or rabbits, indicating pro-angiogenic and pro-fibrotic roles of ROS [36-38]. While an appropriate amount of ROS generation is beneficial to post-MI cardiac repair, excessive ROS are detrimental.

\section{PMN granule components}

PMNs play a critical role in protecting against pathogen infection and non-infectious inflammatory processes, and its functions depend on the exocytosis and release of PMN granule components. There are four types of PMN granules, which combined contain approximately 300 proteins: azurophilic (primary), specific (secondary), gelatinase (tertiary), and secretory granules (Figure 2). Azurophilic granules, the largest, are first formed during PMN maturation and contain myeloperoxidase (MPO), serine proteases, azurocidin, $\alpha$-defensins, lysozyme, and bactericidal/permeability-increasing protein [10]. Specific granules are smaller than azurophilic granules in diameter and contain lactoferrin, neutrophil gelatinase-associated lipocalin (NGAL, lipocalin-2), cathelicidin, and lysozyme [39]. Gelatinase granules are smaller than specific granules and contain multiple matrix metalloproteinases (MMP-8 and -9 in particular) and a few microbicidal materials. Secretory granules consist primarily of complement receptor 1 , plasma protein albumin, CD13 (aminopeptidase N), CD14, and CD16 (Fc gamma receptor III) [10].

PMN granules are sequentially mobilized into the tissue during cell migration. Secretory granules are discharged first, and these components interact with the endothelium and other leukocytes in the circulation. Gelatinase degranulation occurs during transendothelial migration of
PMNs, followed by the release of specific and azurophilic granules at the site of inflammation [40]. In addition to antimicrobial functions, these granule components are involved in a number of inflammation-associated diseases, including MI. Below, we summarize the current literature on the roles of granule components in post-MI LV remodeling. For granule components that have not been studied in the MI setting, we discuss their roles in regulating inflammation and innate immunity.

\section{Granule components evaluated in the MI setting Myeloperoxidase (MPO)}

MPO is an enzyme that catalyzes the oxidation of halide ions to hypohalous acids mediated by hydrogen peroxide, which modifies amino acids and many kinds of macromolecules and affects their normal biological properties [41]. In addition to acting as a key component of the oxygendependent intracellular microbicidal system, MPO is involved in tissue injury and remodeling. MPO is elevated in MI patients and can act as a diagnostic plasma marker of MI [42]. High MPO is also a risk factor for long-term mortality [43]. Post-MI, MPO is secreted by PMNs and macrophages, and it accumulates in infarct regions to oxidize proteins and lipids. MPO deletion in mice reduces leukocyte infiltration and also attenuates LV function and dilatation, which have been shown in part to be due to decreased oxidative inactivation of plasminogen activator inhibitor 1 [44]. In addition, MPO generates cytotoxic products of glycine (formaldehyde) and threonine (acrolein) in the infarct zone, which adversely affects LV remodeling and function in mice [45]. Reactive chlorinating species produced by MPO catalyze plasmalogens to produce the alpha-chloro fatty aldehyde 2-chlorohexadecanal, which elicits myocardial damage and reduces ventricular

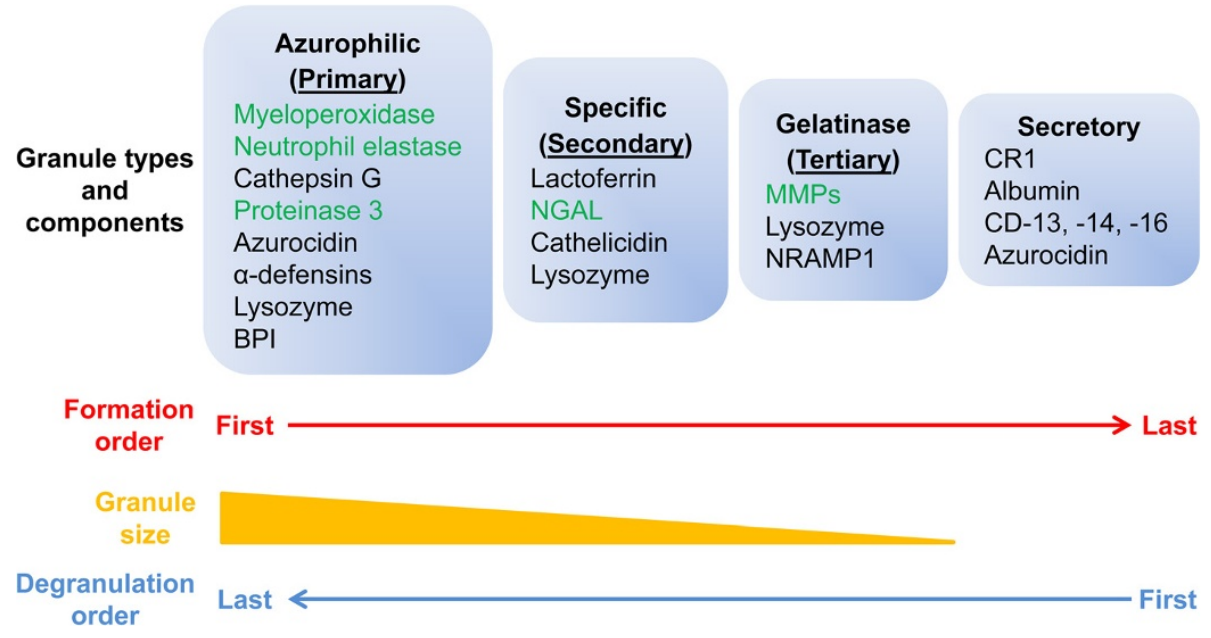

Figure 2 PMN granules. The types, components, formation order, granule size, and degranulation order of PMN granules. The granule components that have been evaluated in the MI setting are highlighted in green. BPI: Bactericidal/permeability-increasing protein; NGAL: neutrophil gelatinase-associated lipocalin; NRAMP1: natural resistance associated macrophage protein-1; CR1: complement receptor 1. 
performance in rats [46]. Targeting MPO signaling may represent a promising way to alleviate MI-induced LV remodeling.

\section{Serine proteases}

Serine proteases stored in azurophilic granules include neutrophil elastase (NE), cathepsin G, proteinase 3, and neutrophil serine protease- 4 . Neutrophil serine protease-4 has recently been identified and shows $39 \%$ identity to NE and proteinase 3 [47]. In the presence of ROS, serine proteinases can break down internalized pathogens, proteolytically degrade cytokines and chemokines, and activate cell surface receptors [48]. In addition, serine proteinases activate the coagulation cascade and platelets to stimulate thrombus formation [49]. During systemic infection, activation of coagulation facilitates compartmentalization of pathogens in liver microvessels and limits infection expansion. In contrast, in the absence of microorganism challenge, coagulation induces large vessel thrombosis and contributes to a risk for MI and stroke.

$\mathrm{NE}$ degrades elastin, collagens, and fibrinogen and contributes to cardiac damage post-MI. NE induces IL-6 secretion to impair cardiac contractility by a nitric oxidedependent pathway [50]. NE can cleave and activate proMMP-9, indicating an interactive action of PMN-derived molecules [51]. NE is released in the early stages of ischemia, and inhibition of NE has been shown to reduce infarct size [52]. Similarly, a selective NE inhibitor protects against myocardial stunning after ischemia/reperfusion in swine [53]. Proteinase 3 is stored in both azurophilic and secretory granules. Proteinase 3 induces endothelial cell apoptosis by caspase-like activity [54], cleaves angiotensinogen to generate angiotensin I and II [55], activates proinflammatory factors (e.g., TNF- $\alpha, \mathrm{IL}-1 \beta$, and IL-18), and degrades extracellular matrix (e.g., fibronectin and collagen IV) [56]. Proteinase 3 levels in the plasma are higher in chronic post-MI patients who later die or are readmitted for heart failure compared to event-free survivors [56]. This indicates that proteinase 3 may exacerbate heart failure and serve as a prognostic marker.

\section{NGAL}

NGAL is a glycoprotein with bacteriostatic properties stored in specific granules of mature PMNs. In humans, NGAL binds directly with MMP-9 to form a high molecular weight complex, protecting MMP-9 from degradation [57]. This binding occurs at the 87 amino acid of the NGAL, which is a cysteine in humans [58]. Mouse NGAL does not have this cysteine and does not bind directly to MMP-9. NGAL levels significantly increase in both rats and patients post-MI and associate with adverse outcomes [59]. High plasma NGAL before intervention has been shown to independently predict all-cause mortality for MI patients treated with primary percutaneous coronary intervention [60]. The NGAL mechanisms of regulating LV remodeling have not been revealed, but may involve both direct interactions with MMP-9 as well as growth factor functions independent of complex formation.

\section{MMP-8}

Despite originally being classified as the neutrophil collagenase, MMP- 8 is secreted not only by PMNs, but also by macrophages [61]. MMP-8 promotes PMN migration by degrading collagens [62], and PMN depletion inhibits early collagen degradation because of the lack of MMP-8 [63]. MMP-8 degrades fibrillar collagen by binding and cleavage of collagen type I $\alpha 1$ and $\alpha 2$ chains [64]. The quantities of total and active MMP-8 were shown to be higher in patients with LV rupture than those without rupture [65], indicating that MMP-8 may promote infarct rupture in humans by degrading collagen.

\section{MMP-9}

MMP-9 is one of the most widely investigated MMPs in cardiovascular disease. Infiltrating PMNs are an early source of MMP-9 after MI both with and without reperfusion in humans and multiple animal models, including mice, rabbits, and canines [66-69]. PMN-derived MMP-9 is stored in gelatinase granules and released upon chemotactic stimulation. MMP-9 is also be secreted by macrophages, myocytes, fibroblasts, vascular smooth muscle cells, and endothelial cells [61]. MMP-9 is significantly elevated in the first week after MI in mice, consistent with the time course of PMN and macrophage infiltration. MMP-9 deletion attenuates LV dysfunction and collagen deposition and promotes angiogenesis post-MI in mice [70,71]. Neutrophil-derived MMP-9 may exert very early effects in the MI setting by degrading extracellular matrix and promoting leukocyte cell infiltration into the infarct area, while MMP-9 from other cells may regulate scar formation $[72,73]$.

\section{Granule components that have not been evaluated in the Ml setting \\ Cathepsin $G$}

Cathepsin G has biphasic regulation of leukocyte chemotaxis, serving as both a stimulator and repressor of chemotaxis. Substrate availability determines its action, as cathepsin G enhances PMN and monocyte chemotaxis by cleaving the N-terminal residues of CXCL5 and CCL15 to increase their chemotactic activities [74]. Conversely, cathepsin G also degrades CCL5, CCL3, CXCL12, and CXCR4 to reduce PMN and monocyte chemotaxis $[75,76]$. Cathepsin $G$ is a potent platelet activator and promotes intravascular thrombosis, thus contributing to the formation of a thrombus clot [77]. 


\section{Azurocidin}

Azurocidin, also known as cationic antimicrobial protein of $37 \mathrm{kDa}$ (CAP37) or heparin-binding protein (HBP), is stored in both azurophilic and secretory granules. Azurocidin is released at both the very early phase and the later phase of PMN recruitment to sites of inflammation [78]. Azurocidin induces monocyte recruitment and enhances cytokine production in monocytes/macrophages, signifying the ability of azurocidin to regulate monocytes/ macrophage infiltration and activation in the post-MI setting [79-81]. The effect of azurocidin on leukocytes is dependent on $\beta_{2}$ integrins and the formyl peptide receptor. Originally considered devoid of proteinase activity, azurocidin can actually cleave insulin-like growth factor binding protein-1, -2 , and -4 in vitro [82]. The LTB4induced increase in vascular permeability is mediated by azurocidin [83], suggesting that azurocidin may promote leukocyte extravasation.

\section{a-defensins}

The $\alpha$-defensins, also referred to as human neutrophil peptides (HNPs), are small cationic antimicrobial peptides mainly present in the azurophilic granules. The $\alpha$-defensins not only have antimicrobial function, but also possess immunoregulatory properties mediated by direct interaction with innate immune cells [84]. HNP-1 and -2 are potent chemoattractants for monocyte, naïve $\mathrm{T}$ cells, and immature dendritic cells, but not for mature dendritic cells or PMNs $[85,86]$. In addition, HNP-1 is able to activate monocyte-derived dendritic cells and upregulate the production of proinflammatory cytokines [87]. In view of their immunoregulatory activities, future studies to explore the functions of $\alpha$-defensins in MI are warranted.

\section{Lactoferrin}

Lactoferrin is an iron-binding glycoprotein of the transferrin family present in the specific granules. It is also synthesized by epithelial cells [88]. In addition to direct antimicrobial activity, lactoferrin inhibits the upregulation of adhesion molecules, limits iron-mediated damage to host tissue, suppresses proinflammatory cytokine production, and limits PMN recruitment [89]. Post-MI, lactoferrin may have protective effects by inhibiting excessive inflammation and ROS production.

\section{Cathelicidin}

Cathelicidin, also known as cathelicidin-related antimicrobial peptide (CRAMP) in mouse and LL-37 or hCAP18 in human, resides in specific granules. In addition to potent microbicidal activity, LL-37 inhibits PMN apoptosis and stimulates monocyte recruitment, angiogenesis, and tissue regeneration [90]. LL37 elevates IL-1 $\beta$-induced release of cytokines (IL-6 and IL-10) and chemokines such as MCP-1, MCP-3, and IL-8 in macrophages [91,92]. LL-37 deposits at sites of endothelial injury, facilitates re-endothelization, and limits neointima formation after stent implantation by enhancing early outgrowth cell recruitment and release of growth factors [93]. Further, stents coated with LL-37 have reduced re-stenosis, indicating that LL-37 may promote the healing response [93]. Doring and colleagues show that lack of CRAMP reduces atherosclerotic lesion size by restraining monocyte recruitment and by reducing the adhesion of classical monocytes and PMNs in a formyl peptide receptor-dependent way [94]. In early stages of atherosclerosis, CRAMP is specifically expressed in PMNs, but not in monocytes or macrophages. Therefore, cathelicidin may modulate LV remodeling after MI by regulating leukocyte infiltration, apoptosis, and angiogenesis.

\section{MMP-25}

MMP-25, also known as MT6-MMP or leukolysin, is a membrane-type MMP. In PMNs, MMP-25 is present in gelatinase granules and is also found in nuclear/endoplasmic reticulum/Golgi fractions [95]. In vitro studies show that MMP-25 cleaves CXCL5, CCL15, and CCL23 to activate these chemokines, and thus promotes the recruitment of PMNs and monocytes

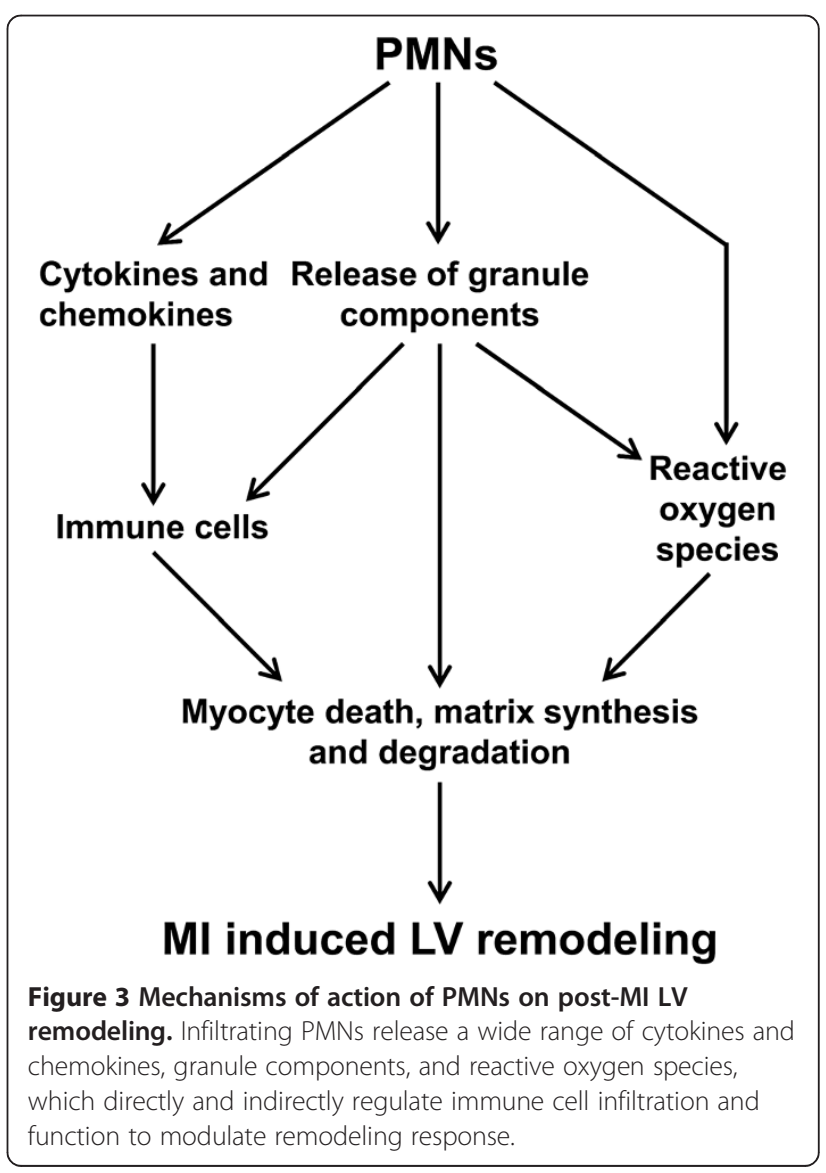


[96]. MMP-25 roles, however, remain unknown, and MMP-25 levels have not even been measured post-MI.

\section{NETs}

PMNs release granule antimicrobial proteins and nuclear components (DNA, histones) into the extracellular environment that form NETs to trap invading pathogens. This process is referred to as NETosis and is an alternative to PMN apoptosis [97]. NETs degrade virulent factors and kill microorganisms to prevent infection from spreading [98]. NETs also have detrimental influences on the host. NETs activate the complement system, and the complement component $\mathrm{Clq}$ can inhibit NETs degradation, thus establishing a positive feedback loop to exacerbate disease progression [99]. It has been shown that NETs facilitate thrombosis in MI patients, probably by promoting fibrin deposition and platelet aggregation [100]. The role of NETs in the progression of MI-induced heart failure, however, has not been investigated.

\section{Conclusions}

This review summarizes the roles of PMNs and PMN-derived granule components in inflammation, innate immunity, and MI. PMNs regulate the post-MI wound healing response through several mechanisms (Figure 3). PMNs are activated by cytokines and chemokines, and activated PMNs in turn release cytokines and chemokines to potentiate the inflammatory component of wound healing [101]. PMN degranulation releases an array of proteases that regulate LV remodeling by modulating immune cell infiltration and function, including ROS production. The PMN respiratory burst generates ROS to directly modify biological molecules. However, several aspects remain to be elucidated in order to better understand PMN roles after MI.

First, PMN roles post-MI need to be better understood, using systematic approaches that distinguish the negative and positive roles. In order for therapeutic strategies to be developed that promote healing while preventing adverse remodeling, we need to better understand the complexity of PMNs in mediating the early inflammatory response.

Second, there may be different activation phenotypes of PMNs following MI [102-104]. A recent study by Fridlender and colleagues suggests that tumor associated PMNs can be polarized towards different phenotypes [104]. Blocking TGF- $\beta$ slows tumor growth by increasing the influx of PMNs to produce higher levels of proinflammatory cytokines, which are more cytotoxic [104]. PMN depletion without TGF- $\beta$ blockade, however, also decreases tumor growth. TGF- $\beta$, therefore, promotes a PMN pro-tumor phenotype, while blocking TGF- $\beta$ induces a PMN anti-tumor phenotype [104]. TGF- $\beta$ effects on tumors and the post-MI LV are likely opposite, as TGF- $\beta$ promotes post-MI infarct healing and blocking
TGF- $\beta$ increases MI-induced mortality and LV dilation [105]. PMN phenotypes should be examined by isolating PMNs from post-MI hearts at different time points and measuring the expression of key effector molecules. Before this can be accomplished, however, we need to determine what markers can be used to differentiate phenotypes and whether overall inflammatory status is sufficient.

Third, whether PMNs directly or indirectly regulate macrophage polarization (M1 or M2 activation) or function is not currently well understood. This could be evaluated by incubating resting macrophages with conditioned media from activated PMNs and monitoring the macrophages for M1 and M2 markers [106]. It may be that PMNs from different post-MI times promote differential macrophage activation patterns.

Fourth, whether PMNs regulate cardiac fibroblast phenotype and post-MI scar formation is not known [107]. The role of macrophages in activating fibroblasts has been studied, but whether PMNs exert similar or different activation functions is unknown. This can be addressed by incubating isolated cardiac fibroblasts with activated PMNs and measuring fibroblast phenotype and secretion of extracellular matrix [106].

In conclusion, understanding how PMNs regulate postMI LV remodeling may provide promising intervention targets for MI patients. Understanding the detrimental and beneficial roles will provide mechanistic insight into how PMNs regulate inflammatory responses, both in the MI setting and in other diseases that have inflammation as a common response.

\section{Abbreviations}

DAMPs: Damage-associated molecular patterns; HNPs: Human neutrophil peptides; ICAMs: Intercellular adhesion molecules; IL: Interleukin;

LTB4: Leukotriene B4; LV: Left ventricle; MCP-1: Monocyte chemoattractant protein-1; MI: Myocardial infarction; MMPs: Matrix metalloproteinases;

MPO: Myeloperoxidase; NE: Neutrophil elastase; NETs: Neutrophil extracellular traps; NGAL: Neutrophil gelatinase-associated lipocalin; ROS: Reactive oxygen species; TLR: Toll-like receptor; TNF: Tumor necrosis factor.

\section{Competing interests}

The authors declare that they have no competing interests.

\section{Authors' contributions}

YM and MLL conceived the concept of the review. YM wrote the first draft. YM, AY, and MLL edited and revised the manuscript. All authors read and approved the final manuscript.

\section{Acknowledgements}

We acknowledge support from NIH/NHLBI HHSN $268201000036 \mathrm{C}$ (N01-HV00244) for the San Antonio Cardiovascular Proteomics Center and R01 HL075360, and from the Biomedical Laboratory Research and Development Service of the Veterans Affairs Office of Research and Development Award 5I01BX000505 to MLL.

\section{Author details}

${ }^{1}$ San Antonio Cardiovascular Proteomics Center, San Antonio, TX, USA. ${ }^{2}$ Jackson Center for Heart Research, Department of Physiology and Biophysics, University of Mississippi Medical Center, Jackson, MS, USA. ${ }^{3}$ Research and Medicine Services, G.V. (Sonny) Montgomery Veterans Affairs Medical Center, Jackson, MS, USA. 
Received: 29 December 2012 Accepted: 11 April 2013

Published: 3 June 2013

\section{References}

1. Day RB, Link DC: Regulation of neutrophil trafficking from the bone marrow. Cell Mol Life Sci 2012, 69:1415-1423.

2. Akpek M, Kaya MG, Lam YY, Sahin O, Elcik D, Celik T, Ergin A, Gibson CM: Relation of neutrophil/lymphocyte ratio to coronary flow to in-hospital major adverse cardiac events in patients with ST-elevated myocardial infarction undergoing primary coronary intervention. Am J Cardiol 2012, 110:621-627.

3. Meissner J, Irfan A, Twerenbold R, Mueller S, Reiter M, Haaf P, Reichlin T, Schaub N, Winkler K, Pfister O, et al: Use of neutrophil count in early diagnosis and risk stratification of AMI. Am J Med 2011, 124:534-542.

4. Chia S, Nagurney JT, Brown DF, Raffel OC, Bamberg F, Senatore F, Wackers FJ, Jang IK: Association of leukocyte and neutrophil counts with infarct size, left ventricular function and outcomes after percutaneous coronary intervention for ST-elevation myocardial infarction. Am J Cardiol 2009, 103:333-337.

5. Jolly SR, Kane WJ, Hook BG, Abrams GD, Kunkel SL, Lucchesi BR: Reduction of myocardial infarct size by neutrophil depletion: effect of duration of occlusion. Am Heart J 1986, 112:682-690.

6. Romson JL, Hook BG, Kunkel SL, Abrams GD, Schork MA, Lucchesi BR: Reduction of the extent of ischemic myocardial injury by neutrophil depletion in the dog. Circulation 1983, 67:1016-1023.

7. Hammerman H, Kloner RA, Hale S, Schoen FJ, Braunwald E: Dosedependent effects of short-term methylprednisolone on myocardial infarct extent, scar formation, and ventricular function. Circulation 1983, 68:446-452

8. Borregaard N, Theilgaard-Monch K, Cowland JB, Stahle M, Sorensen OE: Neutrophils and keratinocytes in innate immunity-cooperative actions to provide antimicrobial defense at the right time and place. J Leukoc Biol 2005, 77:439-443.

9. Barletta KE, Ley K, Mehrad B: Regulation of neutrophil function by adenosine. Arterioscler Thromb Vasc Biol 2012, 32:856-864.

10. Amulic B, Cazalet C, Hayes GL, Metzler KD, Zychlinsky A: Neutrophil function: from mechanisms to disease. Annu Rev Immunol 2012, 30:459-489.

11. Dancey JT, Deubelbeiss KA, Harker LA, Finch CA: Neutrophil kinetics in man. J Clin Invest 1976, 58:705-715.

12. Galli SJ, Borregaard N, Wynn TA: Phenotypic and functional plasticity of cells of innate immunity: macrophages, mast cells and neutrophils. Nat Immunol 2011, 12:1035-1044.

13. Pillay J, den Braber I, Vrisekoop N, Kwast LM, de Boer RJ, Borghans JA, Tesselaar K, Koenderman L: In vivo labeling with $2 \mathrm{H} 2 \mathrm{O}$ reveals a human neutrophil lifespan of 5.4 days. Blood 2010, 116:625-627.

14. Colotta F, Re F, Polentarutti N, Sozzani S, Mantovani A: Modulation of granulocyte survival and programmed cell death by cytokines and bacterial products. Blood 1992, 80:2012-2020.

15. Borregaard N: Neutrophils, from marrow to microbes. Immunity 2010 33:657-670.

16. Mary JY: Normal human granulopoiesis revisited. II. Bone marrow data. Biomed Pharmacother 1985, 39:66-77.

17. Semerad CL, Liu F, Gregory AD, Stumpf K, Link DC: G-CSF is an essential regulator of neutrophil trafficking from the bone marrow to the blood. Immunity 2002, 17:413-423.

18. Ivey CL, Williams FM, Collins PD, Jose PJ, Williams TJ: Neutrophil chemoattractants generated in two phases during reperfusion of ischemic myocardium in the rabbit. Evidence for a role for $\mathrm{C} 5 \mathrm{a}$ and interleukin-8. J Clin Invest 1995, 95:2720-2728.

19. Kim D, Haynes CL: Neutrophil chemotaxis within a competing gradient of chemoattractants. Anal Chem 2012, 84:6070-6078.

20. Frangogiannis NG: Regulation of the inflammatory response in cardiac repair. Circ Res 2012, 110:159-173.

21. Bratton DL, Henson PM: Neutrophil clearance: when the party is over, clean-up begins. Trends Immunol 2011, 32:350-357.

22. Hayashi F, Means TK, Luster AD: Toll-like receptors stimulate human neutrophil function. Blood 2003, 102:2660-2669.

23. Greenblatt MB, Aliprantis A, Hu B, Glimcher LH: Calcineurin regulates innate antifungal immunity in neutrophils. J Exp Med 2010, 207:923-931.
24. Kerrigan AM, Dennehy KM, Mourao-Sa D, Faro-Trindade I, Willment JA, Taylor PR, Eble JA, Reis e Sousa C, Brown GD: CLEC-2 is a phagocytic activation receptor expressed on murine peripheral blood neutrophils. J Immunol 2009, 182:4150-4157.

25. Clarke TB, Davis KM, Lysenko ES, Zhou AY, Yu Y, Weiser JN: Recognition of peptidoglycan from the microbiota by Nod1 enhances systemic innate immunity. Nat Med 2010, 16:228-231.

26. Tamassia N, Le Moigne V, Rossato M, Donini M, McCartney S, Calzetti F, Colonna M, Bazzoni F, Cassatella MA: Activation of an immunoregulatory and antiviral gene expression program in poly(l:C)-transfected human neutrophils. J Immunol 2008, 181:6563-6573.

27. Timmers L, Pasterkamp G, de Hoog VC, Arslan F, Appelman Y, de Kleijn DP. The innate immune response in reperfused myocardium. Cardiovasc Res 2012, 94:276-283.

28. Prince LR, Whyte MK, Sabroe I, Parker LC: The role of TLRs in neutrophil activation. Curr Opin Pharmacol 2011, 11:397-403.

29. Ma Y, Zhang X, Bao H, Mi S, Cai W, Yan H, Wang Q, Wang Z, Yan J, Fan G, et al: Toll-like receptor (TLR) 2 and TLR4 differentially regulate doxorubicin induced cardiomyopathy in mice. PLoS One 2012, 7:e40763.

30. Ueno H, Matsuda T, Hashimoto S, Amaya F, Kitamura Y, Tanaka M, Kobayashi A, Maruyama I, Yamada S, Hasegawa N, et al: Contributions of high mobility group box protein in experimental and clinical acute lung injury. Am J Respir Crit Care Med 2004, 170:1310-1316.

31. Furze RC, Rankin SM: Neutrophil mobilization and clearance in the bone marrow. Immunology 2008, 125:281-288.

32. Soehnlein O, Lindbom L: Phagocyte partnership during the onset and resolution of inflammation. Nat Rev Immunol 2010, 10:427-439.

33. Esmann L, Idel C, Sarkar A, Hellberg L, Behnen M, Moller S, van Zandbergen G, Klinger M, Kohl J, Bussmeyer U, et al: Phagocytosis of apoptotic cells by neutrophil granulocytes: diminished proinflammatory neutrophil functions in the presence of apoptotic cells. J Immunol 2010, 184:391-400.

34. Ciz M, Denev P, Kratchanova M, Vasicek O, Ambrozova G, Lojek A: Flavonoids inhibit the respiratory burst of neutrophils in mammals. Oxid Med Cell Longev 2012, 2012:181295.

35. Kleniewska P, Piechota A, Skibska B, Goraca A: The NADPH oxidase family and its inhibitors. Arch Immunol Ther Exp (Warsz) 2012, 60:277-294.

36. Liu XH, Pan LL, Deng HY, Xiong QH, Wu D, Huang GY, Gong QH, Zhu YZ: Leonurine (SCM-198) attenuates myocardial fibrotic response via inhibition of NADPH oxidase 4. Free Radic Biol Med 2013, 54:93-104.

37. Qin F, Simeone M, Patel R: Inhibition of NADPH oxidase reduces myocardial oxidative stress and apoptosis and improves cardiac function in heart failure after myocardial infarction. Free Radic Biol Med 2007, 43:271-281.

38. Zhao W, Zhao T, Chen Y, Ahokas RA, Sun Y: Reactive oxygen species promote angiogenesis in the infarcted rat heart. Int J Exp Pathol 2009, 90:621-629.

39. Faurschou M, Borregaard N: Neutrophil granules and secretory vesicles in inflammation. Microbes Infect 2003, 5:1317-1327.

40. Soehnlein O, Weber C, Lindbom L: Neutrophil granule proteins tune monocytic cell function. Trends Immunol 2009, 30:538-546.

41. Prokopowicz Z, Marcinkiewicz J, Katz DR, Chain BM: Neutrophil myeloperoxidase: soldier and statesman. Arch Immunol Ther Exp (Warsz) 2012, 60:43-54.

42. Rudolph V, Goldmann BU, Bos C, Rudolph TK, Klinke A, Friedrichs K, Lau D, Wegscheider K, Haddad M, Meinertz T, Baldus S: Diagnostic value of MPO plasma levels in patients admitted for suspected myocardial infarction. Int J Cardiol 2011, 153:267-271.

43. Mocatta TJ, Pilbrow AP, Cameron VA, Senthilmohan R, Frampton CM, Richards AM, Winterbourn CC: Plasma concentrations of myeloperoxidase predict mortality after myocardial infarction. J Am Coll Cardiol 2007, 49:1993-2000.

44. Askari AT, Brennan ML, Zhou X, Drinko J, Morehead A, Thomas JD, Topol EJ, Hazen SL, Penn MS: Myeloperoxidase and plasminogen activator inhibitor 1 play a central role in ventricular remodeling after myocardial infarction. J Exp Med 2003, 197:615-624.

45. Vasilyev N, Williams T, Brennan ML, Unzek S, Zhou X, Heinecke JW, Spitz DR, Topol EJ, Hazen SL, Penn MS: Myeloperoxidase-generated oxidants modulate left ventricular remodeling but not infarct size after myocardial infarction. Circulation 2005, 112:2812-2820.

46. Thukkani AK, Martinson BD, Albert CJ, Vogler GA, Ford DA: Neutrophilmediated accumulation of 2-CIHDA during myocardial infarction: 2-ClHDA-mediated myocardial injury. Am J Physiol Heart Circ Physiol 2005, 288:H2955-H2964. 
47. Perera NC, Schilling O, Kittel H, Back W, Kremmer E, Jenne DE: NSP4, an elastase-related protease in human neutrophils with arginine specificity. Proc Natl Acad Sci U S A 2012, 109:6229-6234.

48. Pham CT: Neutrophil serine proteases: specific regulators of inflammation. Nat Rev Immunol 2006, 6:541-550

49. Afshar-Kharghan $\mathrm{V}$, Thiagarajan P: Leukocyte adhesion and thrombosis. Curr Opin Hematol 2006, 13:34-39.

50. Yu X, Kennedy RH, Liu SJ: JAK2/STAT3, not ERK1/2, mediates interleukin-6 -induced activation of inducible nitric-oxide synthase and decrease in contractility of adult ventricular myocytes. J Biol Chem 2003, 278:16304-16309.

51. Jackson PL, Xu X, Wilson L, Weathington NM, Clancy JP, Blalock JE, Gaggar A: Human neutrophil elastase-mediated cleavage sites of MMP-9 and TIMP-1: implications to cystic fibrosis proteolytic dysfunction. Mol Med 2010, 16:159-166.

52. Bidouard JP, Duval N, Kapui Z, Herbert JM, O'Connor SE, Janiak P: SSR69071, an elastase inhibitor, reduces myocardial infarct size following ischemia-reperfusion injury. Eur J Pharmacol 2003, 461:49-52.

53. Akiyama D, Hara T, Yoshitomi O, Maekawa T, Cho S, Sumikawa K: Postischemic infusion of sivelestat sodium hydrate, a selective neutrophil elastase inhibitor, protects against myocardial stunning in swine. J Anesth 2010, 24:575-581.

54. Pendergraft WF 3rd, Rudolph EH, Falk R, Jahn JE, Grimmler M, Hengst L, Jennette JC, Preston GA: Proteinase 3 sidesteps caspases and cleaves p21(Waf1/Cip1/ Sdi1) to induce endothelial cell apoptosis. Kidney Int 2004, 65:75-84.

55. Ramaha A, Patston PA: Release and degradation of angiotensin I and angiotensin II from angiotensinogen by neutrophil serine proteinases. Arch Biochem Biophys 2002, 397:77-83.

56. Ng LL, Khan SQ, Narayan H, Quinn P, Squire IB, Davies JE: Proteinase 3 and prognosis of patients with acute myocardial infarction. Clin Sci (Lond) 2011, 120:231-238

57. Yan L, Borregaard N, Kjeldsen L, Moses MA: The high molecular weight urinary matrix metalloproteinase (MMP) activity is a complex of gelatinase B/MMP-9 and neutrophil gelatinase-associated lipocalin (NGAL). Modulation of MMP-9 activity by NGAL. J Biol Chem 2001, 276:37258-37265.

58. Coles M, Diercks T, Muehlenweg B, Bartsch S, Zolzer V, Tschesche H, Kessler $\mathrm{H}$ : The solution structure and dynamics of human neutrophil gelatinaseassociated lipocalin. J Mol Biol 1999, 289:139-157.

59. Yndestad A, Landro L, Ueland T, Dahl CP, Flo TH, Vinge LE, Espevik T, Froland SS, Husberg C, Christensen G, et al: Increased systemic and myocardial expression of neutrophil gelatinase-associated lipocalin in clinical and experimental heart failure. Eur Heart J 2009, 30:1229-1236.

60. Lindberg S, Pedersen SH, Mogelvang R, Jensen JS, Flyvbjerg A, Galatius S, Magnusson NE: Prognostic utility of neutrophil gelatinase-associated lipocalin in predicting mortality and cardiovascular events in patients with ST-segment elevation myocardial infarction treated with primary percutaneous coronary intervention. J Am Coll Cardiol 2012, 60:339-345.

61. Lindsey ML, Zamilpa R: Temporal and spatial expression of matrix metalloproteinases and tissue inhibitors of metalloproteinases following myocardial infarction. Cardiovasc Ther 2012, 30:31-41.

62. Lin M, Jackson P, Tester AM, Diaconu E, Overall CM, Blalock JE, Pearlman E: Matrix metalloproteinase- 8 facilitates neutrophil migration through the corneal stromal matrix by collagen degradation and production of the chemotactic peptide Pro-Gly-Pro. Am J Pathol 2008, 173:144-153.

63. Harty MW, Muratore CS, Papa EF, Gart MS, Ramm GA, Gregory SH, Tracy TF $\mathrm{Jr}$ : Neutrophil depletion blocks early collagen degradation in repairing cholestatic rat livers. Am J Pathol 2010, 176:1271-1281.

64. Gioia M, Monaco S, Fasciglione GF, Coletti A, Modesti A, Marini S, Coletta M: Characterization of the mechanisms by which gelatinase $A$, neutrophil collagenase, and membrane-type metalloproteinase MMP-14 recognize collagen I and enzymatically process the two alpha-chains. J Mol Biol 2007, 368:1101-1113.

65. van den Borne SW, Cleutjens JP, Hanemaaijer R, Creemers EE, Smits JF, Daemen MJ, Blankesteijn WM: Increased matrix metalloproteinase-8 and -9 activity in patients with infarct rupture after myocardial infarction. Cardiovasc Pathol 2009, 18:37-43.

66. Romanic AM, Harrison SM, Bao W, Burns-Kurtis CL, Pickering S, Gu J, Grau E Mao J, Sathe GM, Ohlstein EH, Yue TL: Myocardial protection from ischemia/reperfusion injury by targeted deletion of matrix metalloproteinase-9. Cardiovasc Res 2002, 54:549-558.
67. Lindsey M, Wedin K, Brown MD, Keller C, Evans AJ, Smolen J, Burns AR, Rossen RD, Michael L, Entman M: Matrix-dependent mechanism of neutrophil-mediated release and activation of matrix metalloproteinase 9 in myocardial ischemia/reperfusion. Circulation 2001, 103:2181-2187.

68. Romanic AM, Burns-Kurtis CL, Gout B, Berrebi-Bertrand I, Ohlstein EH: Matrix metalloproteinase expression in cardiac myocytes following myocardial infarction in the rabbit. Life Sci 2001, 68:799-814.

69. Kelly D, Cockerill G, Ng LL, Thompson M, Khan S, Samani NJ, Squire IB: Plasma matrix metalloproteinase- 9 and left ventricular remodelling after acute myocardial infarction in man: a prospective cohort study. Eur Heart J 2007, 28:711-718.

70. Ducharme A, Frantz S, Aikawa M, Rabkin E, Lindsey M, Rohde LE, Schoen FJ, Kelly RA, Werb Z, Libby P, Lee RT: Targeted deletion of matrix metalloproteinase- 9 attenuates left ventricular enlargement and collagen accumulation after experimental myocardial infarction. $J$ Clin Invest 2000, 106:55-62.

71. Lindsey ML, Escobar GP, Dobrucki LW, Goshorn DK, Bouges S, Mingoia JT, McClister DM Jr, Su H, Gannon J, MacGillivray C, et al: Matrix metalloproteinase-9 gene deletion facilitates angiogenesis after myocardial infarction. Am J Physiol Heart Circ Physiol 2006, 290:H232-H239.

72. Yabluchanskiy A, Li Y, Chilton RJ, Lindsey ML: Matrix metalloproteinases: drug targets for myocardial infarction. Curr Drug Targets 2013, 14:276-286.

73. Zamilpa R, Ibarra J, de Castro Bras LE, Ramirez TA, Nguyen N, Halade GV, Zhang J, Dai Q, Dayah T, Chiao YA, et al: Transgenic overexpression of matrix metalloproteinase- 9 in macrophages attenuates the inflammatory response and improves left ventricular function post-myocardial infarction. J Mol Cell Cardiol 2012, 53:599-608.

74. Richter R, Bistrian R, Escher S, Forssmann WG, Vakili J, Henschler R, Spodsberg N, Frimpong-Boateng A, Forssmann U: Quantum proteolytic activation of chemokine CCL15 by neutrophil granulocytes modulates mononuclear cell adhesiveness. J Immunol 2005, 175:1599-1608.

75. Pham CT: Neutrophil serine proteases fine-tune the inflammatory response. Int J Biochem Cell Biol 2008, 40:1317-1333.

76. Lim JK, Lu W, Hartley O, DeVico AL: N-terminal proteolytic processing by cathepsin G converts RANTES/CCL5 and related analogs into a truncated 4-68 variant. J Leukoc Biol 2006, 80:1395-1404.

77. Herrmann SM, Funke-Kaiser H, Schmidt-Petersen K, Nicaud V, GautierBertrand M, Evans A, Kee F, Arveiler D, Morrison C, Orzechowski HD, et al: Characterization of polymorphic structure of cathepsin $\mathrm{G}$ gene: role in cardiovascular and cerebrovascular diseases. Arterioscler Thromb Vasc Biol 2001, 21:1538-1543.

78. Tapper H, Karlsson A, Morgelin M, Flodgaard H, Herwald H: Secretion of heparinbinding protein from human neutrophils is determined by its localization in azurophilic granules and secretory vesicles. Blood 2002, 99:1785-1793.

79. Soehnlein O, Lindbom L: Neutrophil-derived azurocidin alarms the immune system. J Leukoc Biol 2009, 85:344-351.

80. Rasmussen PB, Bjorn S, Hastrup S, Nielsen PF, Norris K, Thim L, Wiberg FC, Flodgaard H: Characterization of recombinant human HBP/CAP37/azurocidin, a pleiotropic mediator of inflammation-enhancing LPS-induced cytokine release from monocytes. FEBS Lett 1996, 390:109-112.

81. Soehnlein O, Kai-Larsen Y, Frithiof R, Sorensen OE, Kenne E, ScharffetterKochanek K, Eriksson EE, Herwald H, Agerberth B, Lindbom L: Neutrophil primary granule proteins HBP and HNP1-3 boost bacterial phagocytosis by human and murine macrophages. J Clin Invest 2008, 118:3491-3502.

82. Brandt K, Lundell K, Brismar K: Neutrophil-derived azurocidin cleaves insulin-like growth factor-binding protein-1, -2 and -4. Growth Horm IGF Res 2011, 21:167-173.

83. Di Gennaro A, Kenne E, Wan M, Soehnlein O, Lindbom L, Haeggstrom JZ: Leukotriene B4-induced changes in vascular permeability are mediated by neutrophil release of heparin-binding protein (HBP/CAP37/ azurocidin). FASEB J 2009, 23:1750-1757.

84. Yang D, Biragyn A, Hoover DM, Lubkowski J, Oppenheim JJ: Multiple roles of antimicrobial defensins, cathelicidins, and eosinophil-derived neurotoxin in host defense. Annu Rev Immunol 2004, 22:181-215.

85. Yang D, Chen Q, Chertov O, Oppenheim JJ: Human neutrophil defensins selectively chemoattract naive $\mathrm{T}$ and immature dendritic cells. J Leukoc Biol 2000, 68:9-14

86. Territo MC, Ganz T, Selsted ME, Lehrer R: Monocyte-chemotactic activity of defensins from human neutrophils. J Clin Invest 1989, 84:2017-2020.

87. Presicce P, Giannelli S, Taddeo A, Villa ML, Della Bella S: Human defensins activate monocyte-derived dendritic cells, promote the production of 
proinflammatory cytokines, and up-regulate the surface expression of CD91. J Leukoc Biol 2009, 86:941-948.

88. Ward PP, Paz E, Conneely OM: Multifunctional roles of lactoferrin: a critical overview. Cell Mol Life Sci 2005, 62:2540-2548.

89. Crouch SP, Slater KJ, Fletcher J: Regulation of cytokine release from mononuclear cells by the iron-binding protein lactoferrin. Blood 1992, 80:235-240

90. Bucki R, Leszczynska K, Namiot A, Sokolowski W: Cathelicidin LL-37: a multitask antimicrobial peptide. Arch Immunol Ther Exp (Warsz) 2010, 58:15-25.

91. Lai Y, Gallo RL: AMPed up immunity: how antimicrobial peptides have multiple roles in immune defense. Trends Immunol 2009, 30:131-141.

92. Scott MG, Davidson DJ, Gold MR, Bowdish D, Hancock RE: The human antimicrobial peptide LL-37 is a multifunctional modulator of innate immune responses. J Immunol 2002, 169:3883-3891.

93. Soehnlein O, Wantha S, Simsekyilmaz S, Doring Y, Megens RT, Mause SF, Drechsler M, Smeets R, Weinandy S, Schreiber F, et al: Neutrophil-derived cathelicidin protects from neointimal hyperplasia. Sci Transl Med 2011, 3:103ra198.

94. Doring Y, Drechsler M, Wantha S, Kemmerich K, Lievens D, Vijayan S, Gallo RL, Weber C, Soehnlein O: Lack of neutrophil-derived CRAMP reduces atherosclerosis in mice. Circ Res 2012, 110:1052-1056.

95. Fortin CF, Sohail A, Sun Q, McDonald PP, Fridman R, Fulop T: MT6-MMP is present in lipid rafts and faces inward in living human PMNs but translocates to the cell surface during neutrophil apoptosis. Int Immunol 2010, 22:637-649.

96. Starr AE, Bellac CL, Dufour A, Goebeler V, Overall CM: Biochemical characterization and $\mathrm{N}$-terminomics analysis of leukolysin, the membrane-type 6 matrix metalloprotease (MMP25): chemokine and vimentin cleavages enhance cell migration and macrophage phagocytic activities. J Biol Chem 2012, 287:13382-13395.

97. Remijsen Q, Kuijpers TW, Wirawan E, Lippens S, Vandenabeele P, Vanden Berghe T: Dying for a cause: NETosis, mechanisms behind an antimicrobial cell death modality. Cell Death Differ 2011, 18:581-588.

98. Brinkmann V, Reichard U, Goosmann C, Fauler B, Uhlemann Y, Weiss DS, Weinrauch Y, Zychlinsky A: Neutrophil extracellular traps kill bacteria. Science 2004, 303:1532-1535.

99. Leffler J, Martin M, Gullstrand B, Tyden H, Lood C, Truedsson L, Bengtsson AA, Blom AM: Neutrophil extracellular traps that are not degraded in systemic lupus erythematosus activate complement exacerbating the disease. J Immunol 2012, 188:3522-3531.

100. de Boer OJ, Li X, Teeling P, Mackaay C, Ploegmakers HJ, van der Loos CM Daemen MJ, de Winter RJ, van der Wal AC: Neutrophils, neutrophil extracellular traps and interleukin-17 associate with the organisation of thrombi in acute myocardial infarction. Thromb Haemost 2013, 109:290-297.

101. Soehnlein O, Zernecke A, Eriksson EE, Rothfuchs AG, Pham CT, Herwald H, Bidzhekov K, Rottenberg ME, Weber C, Lindbom L: Neutrophil secretion products pave the way for inflammatory monocytes. Blood 2008, 112:1461-1471.

102. Tsuda Y, Takahashi H, Kobayashi M, Hanafusa T, Herndon DN, Suzuki F: Three different neutrophil subsets exhibited in mice with different susceptibilities to infection by methicillin-resistant Staphylococcus aureus. Immunity 2004, 21:215-226.

103. Mantovani A, Cassatella MA, Costantini C, Jaillon S: Neutrophils in the activation and regulation of innate and adaptive immunity. Nat Rev Immunol 2011, 11:519-531.

104. Fridlender ZG, Sun J, Kim S, Kapoor V, Cheng G, Ling L, Worthen GS, Albelda SM: Polarization of tumor-associated neutrophil phenotype by TGF-beta: "N1" versus "N2" TAN. Cancer Cell 2009, 16:183-194.

105. Frantz S, Hu K, Adamek A, Wolf J, Sallam A, Maier SK, Lonning S, Ling H, Ertl $G$, Bauersachs J: Transforming growth factor beta inhibition increases mortality and left ventricular dilatation after myocardial infarction. Basic Res Cardiol 2008, 103:485-492.
106. Ma Y, Halade GV, Zhang J, Ramirez TA, Levin D, Voorhees A, Jin YF, Han HC, Manicone AM, Lindsey ML: Matrix metalloproteinase-28 deletion exacerbates cardiac dysfunction and rupture after myocardial infarction in mice by inhibiting $\mathrm{m} 2$ macrophage activation. Circ Res 2013, 112:675-688.

107. Ma Y, Halade GV, Lindsey ML: Extracellular matrix and fibroblast communication following myocardial infarction. I Cardiovasc Transl Res 2012, 5:848-857.

doi:10.1186/1755-1536-6-11

Cite this article as: Ma et al:: Neutrophil roles in left ventricular remodeling following myocardial infarction. Fibrogenesis \& Tissue Repair 2013 6:11.

\section{Submit your next manuscript to BioMed Central and take full advantage of:}

- Convenient online submission

- Thorough peer review

- No space constraints or color figure charges

- Immediate publication on acceptance

- Inclusion in PubMed, CAS, Scopus and Google Scholar

- Research which is freely available for redistribution

Submit your manuscript at www.biomedcentral.com/submit
Ciomed Central 